\title{
The Impact of Switch Leadership on Project Success: Empirical Evidence from UAE
}

\author{
Muhammad Tahir (PMP) \\ Prof. Dr. Hummayoun Naeem \\ Department of Management Sciences, SZABIST, Dubai Campus, \\ Dubai International Academic City, United Arab Emirates (UAE)
}

doi: 10.19044/esj.2017.v13n22p241 URL:http://dx.doi.org/10.19044/esj.2017.v13n22p241

\begin{abstract}
This research project documents an empirical analysis of the switch leadership in project management practices in U.A.E. This is an examination study for which 50 projects were studied representing in U.A.E. The main objective of this research is to study the project leadership phenomenon whereas the impact of switch leadership that plays a pivotal role in achieving project success whiles the inclusion of project manager's experience. Since the U.A.E has a diverse working environment and it is multicultural research study that represents the present day project environment in U.A.E. The results from the analysis of data obtained through questionnaires, which further explores the degree of impact of switch leadership between distinctive leadership styles and project success and also it was discovered that project manager's experience does not significantly moderates the relationship between switch leadership and project success. At the end the researcher provides suggestive recommendations for switch in leadership styles displaying the impact on project success.
\end{abstract}

Keywords: Switch Leadership, Project Success, Impact, Empirical Evidence, idealized influence, UAE.

\section{Introduction}

The impact of switch leadership on project success, the study, attempts to documents an empirical analysis of switch leadership in project management practices. Switch leadership is the conscious ability to manoeuvre from one leadership approach to another to enhance performance on a project. It is more in the domain of situational leadership approaches. The project manager should also display flexibility in their leadership actions towards certain team members, by switching their relationship behaviours. 
This paper explores these two facets of a project manager leadership approach, switch leadership style and project success.

\section{1: Background Discussion}

"Project leaders must have this ability to display leadership and their chosen style will substantially affect overall project performance" (Odusami, Iyagba, \&Omirin, 2003). Kerzner (2003) affirms that "Project managers are under a severe time constraint" and ads that a project manager may have to use the situational leadership model to provide individual leadership for each team member. Effective project manager leadership is an important success factor on projects. The capabilities of the people involved in resolving extraordinary situation sand unforeseen problems are an important key for project success (Pinto 1986;Pinto and Slevin, 1988a; Zielasek, 1995).Leadership behaviours are flexible. It would be a mistake to assume that once identified as possessing a certain style, it is impossible to alter that style for different circumstances or situations." In fact successful project managers have been shown to employ a great deal of flexibility in their use of leadership approaches" (Slevin \& Pinto, 2004, p. 74). " To be a great leader and get results, do not just act and react as you naturally do, but truly choose to combine the behaviours needed with the proper leadership style in a given situation " ( General Alexander M. patch - n.d ).

Pinto and Slevin's (1987) project implementation profile (PIP) contains practical aspects of the project work, or the management process, that can be controlled by the project manager or the project team so as to increase the chance of achieving a successful outcome.

\section{2: Problem statement}

Aforementioned discussion about the topic reveals that switch leadership style in the project is vital to the project success; this phenomenon has been investigated in other parts of the world. Since U.A.E has diverse corporate culture which is different from the rest of the world, therefore the researcher plans to investigate and analyse the impact of switch leadership on project success in U.A.E.

\section{3: Objectives of the study}

The purpose of this study is to investigate and analyse switch leadership and project success phenomenon in the U.A.E, which includes the Analysis of switch leadership (IV) in project management practices and to study the notion of Project success (DV) in project management field. It also aimed to analyse the Relationship between Switch leadership (IV) and project success (DV) and also to examine the moderating effect of the project 
manager's experience (MV) on the relationship between Switch leadership (IV) and project success (DV).

\section{4: Significance of the Study}

This study will assess the relationship between switch leadership and project success, and also define and quantitatively relate switches in leadership approaches with success on projects. This kind of study on switch leadership and project success has never been conducted in U.A.E, and it will be a significant contribution toward the selected area of research. This study will provide a guideline for project managers who wish to increase the overall project success in the UAE.

\section{5: Scope \& limitation of the study}

This research is limited to the project leadership approach and the impact of switch leadership on project success phenomenon in U.A.E.

\section{Literature Review}

This section represents the concepts, theories, definitions and related studies on switch leadership and its impact on project success and also affects of project manager's experience, for a more in-depth analysis.

\section{1: Theoretical Perspective}

An intensive and extensive literature review on switch leadership and project success reveals that the success of a project as well as the switch leadership behaviour that affect this success are considered in a various ways by different project leadership scholars. This study had been carried out by researchers in different parts of the world with different sample size that apply to all types of the projects irrespective of culture, geography, age, gender, religion and personality factors.

In this respect, "Prabhakar, Switch leadership in projects (2005)" generalize that idealized influence is an important leader quality that has an impact on project success. It must be utilized as a part of conjunction with relationship practices. Project manager experience aides build up a thought on how and when to utilize different styles to accomplish a success on projects. Qualitative data suggested that project managers exercise "switch leadership" deliberately or not with the point of creating a more effective result. The quantitative results demonstrates that there is no huge connection have been discovered coming from the sample data, so no clear agreement has been established of the impact of "switch leadership" on project success. Future research is obliged to further characterize and quantitatively relate switches in leadership approaches with success on projects. As of 
"Blanchard et al (2008)" situational leadership styles are divided into four categories: Directing, coaching, supporting and delegating.

As discussed by Smith (1989), the situational leadership model states that," contrast between the adequacy and ineffectualness of the four leadership styles is the appropriateness of the leader's behaviour to the specific circumstance in which it is utilized". Effective leaders ought to be adaptable and can change their styles as followers and situations change over time in workplace. Situational leadership contends that to be successful managers we need to adjust our styles, according to the maturity of our people to carry out the task them working on.

The literature on general management research often identifies leadership style as a critical success factor impacting individual and organizational performance. The recent literature on project management to determine whether project management researchers consider leadership style a critical success factor when managing projects and whether they believe leadership style impacts project outcome. It then looks at the literature on project management and discusses the research on the relationship between a project manager's leadership style and competence and their project's outcome and success.

Situational leadership model demonstrate likewise calls attention to that if the right style is utilized to the lower-status adherents, then they will develop and become in their capacity and ability to perform and confidence. According to Hersey (2009) "situational leadership model is about being more effective as a leader".

Project success is probably the most frequently discussed topic in the field of project management, yet it is the least agreed upon. Jeffrey K. Pinto \& Dennis P. Slevin (1988) "Project success is proposed to have two noteworthy parts: issues managing the project itself and issues managing the customer. The sub-issues of time, cost, performance, use, satisfaction, and effectiveness are presented along with items for their measurement".

The literature on project success factors has largely ignored the impact of the project manager experience, and his or her leadership style and competence, on project success. This may be because most of the studies asked project managers their opinion and the respondents have not given due consideration to their own impact on project success. Or, it may be because the studies have not measured the impact of the project manager experience and, thus, not recorded it. Or, it may be because the project manager has no impact. However, that last conclusion is in direct contrast to the general management literature, which postulates that the leadership style and competence of the manager has a direct and measurable impact on the performance of the organization or business. 
An age as a moderating variable used by the researcher (Laura Innocenti, Silvia Profili, Alessia Sammarra 2013) "Analysed whether the effect of HR development practices on job satisfaction (JS) and affective commitment is moderated by age. Moderating variable can provide a more illustrative account of how dependent variables are related to independent variables.

\section{2: Hypotheses Development}

Following hypotheses are postulated and tested:

H1: Higher the frequency of Switch in Leadership Style, the greater would be the chances of overall project success.

H0: Higher the frequency of Switch in Leadership Style does not Produces Overall Success on Projects.

H2: The relationship between switch leadership and project success gets positively moderated by the experience of the project manager.

H0: The relationship between switch leadership and project success does not get positively moderated by the experience of the project manager.

\section{3: Schematic Diagram}

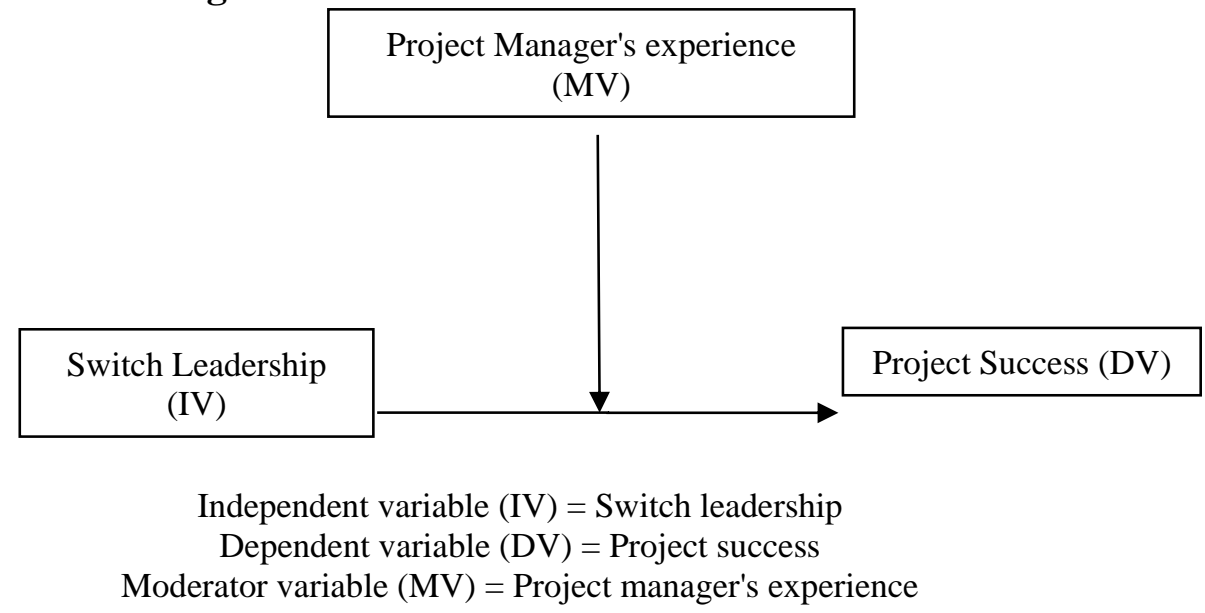

\section{Research Methodology}

Empirical research has two methods, qualitative and quantitative. The methods differ from each other; qualitative research explores attitude, behaviour and experience in such methods as questioning a focused group. As of Clayton, 'qualitative research aims to gather in-depth understanding from human behaviour.' Quantitative on the other hand tend to generate statistics through a use of large scale research, using approach like structured interviews and it tend to reach more people than qualitative method, et al., (Clayton 2010), Quantitative research will be used in this thesis.

\section{1: Population}


Population refers to the entire group of people, events, or things of interest that the researcher wishes to investigate. In this research Project Managers in U.A.E will be the population of research, irrespective of industry, culture, age, gender, religion and personality factors.

\section{2: Research Design}

A sampling frame is the source material or device from which a sample is drawn. It is a list of all those within a population who can be sampled, and may include individuals, households or institutions.

A sample is a subset of the population which comprises some members selected from the population. In probability sampling, the elements in the population have some known chance or probability of being selected as sample subjects, and in non-probability sampling, the elements in the population do not have some known chance or probability of being selected as sample subjects.

The systematic sampling design involves drawing every $n($ th $)$ element in the population starting with a randomly chosen element between 1 and $\mathrm{n}$. A sample size of 50 is used in this research. Due to lack of apparent sampling frame, researcher used non-probability purposive sampling and the sample size was 50 .

\section{3: Research Instrument}

The intensive and extensive literature review reveals the tools have been used by other researchers, out of those two questionnaires are selected to investigate the factors that contributed to switch leadership behaviour and project success. The Situational Leadership Style Summary/Self-Assessment Adapted from, (Hersey and Blanchard) and Project Implementation profile PIP (Project Success), 1987, by Jeffrey K. Pinto and Dennis P. Slevin.

\section{4: Respondents of the Study}

The respondents of the study were project managers in U.A.E, regardless of industry specific or gender.

\section{5: Data collection procedure}

The data collection instrument (Survey questionnaire) was distributed face to face to respondents and to a few respondents by email.

\section{6: Reliability \& validity of research instrument}

To assess the reliability and validity of research instrument, the data of a sample of 50 respondents were used by using Cronbach's reliability test and the following data was obtained: 


\begin{tabular}{|c|c|}
\hline \multicolumn{2}{|c|}{ Reliability Statistics } \\
\hline Cronbach's Alpha & N of Items \\
\hline .629 & 24 \\
\hline
\end{tabular}

The outcome of reliability test indicates that data is highly reliable to proceed for further analysis.

\section{7: Statistical Tool analysis}

The statistics analysis tool SPSS, Ver-20 was used to analyse the data collected through research instrument questionnaire.

\section{Presentation, Analysis and Interpretation of Data} (Tables/Figures)

\section{3: Regression Analysis}

The model is being tested with empirical evidence. The researcher has used Switch in leadership style as the Independent Variable (IV) and Project success as the Dependent Variable (DV), and also the experience of the project manager as the moderating variable (MV). The following hypotheses were postulated;

* H1: Higher the frequency of Switch in Leadership Style, the greater would be the chances of overall project success.

* H2: The relationship between switch leadership and project success gets positively moderated by the experience of the project manager.

The hypotheses are being tested by using the Regression Analysis.

Following are the findings of the regression analysis,

Data reliability test, Cronbach's Alpha:

To assess the reliability of the data, the sample of 50 respondents are used;

\begin{tabular}{|c|c|}
\hline \multicolumn{2}{|c|}{ Reliability Statistics } \\
\hline Cronbach's Alpha & N of ltems \\
\hline .629 & 24 \\
\hline
\end{tabular}

Testing of Model-1 \& Model-2

\begin{tabular}{|c|c|c|c|c|c|c|}
\hline \multicolumn{7}{|c|}{ Model Summary } \\
\hline Model & R & $R^{2}$ & $\begin{array}{c}\text { Adjusted } \\
\text { R2 }\end{array}$ & Beta & T & P-Value \\
\hline Model - 1 ( IV and DV ) & $0.114^{\mathrm{a}}$ & 0.013 & -0.007 & -0.114 & -0.797 & 0.429 \\
\hline Model - 2 ( IV, MV and DV ) & $0.147^{\mathrm{a}}$ & 0.022 & -0.02 & -0.093 & -0.645 & 0.597 \\
\hline
\end{tabular}




\subsection{1: Analysis of Model - 1}

The $\mathrm{R}$ value (0.114) indicates very week relationship between switch leadership (IV) and project success variables (DV).

$\mathrm{R}$-squared value indicates the rate of change in the dependent variable caused by the intervention of independent variable. Since the Rsquared value is 0.013 , indicating almost no relationship between IV \& DV. Adjusted R- Squared is more precise picture minus residual, whereas the negative adjusted R-Squared indicates the tendency toward negative relationship between IV \& DV.

The Beta value $(-0.114)$ indicating the negative relationship between IV \& DV and the independent variable has very less effect on dependent variable.

The $(\mathrm{t})$ test negative value $(-0.797)$ indicates the inverse relationship between IV \& DV.

The (level of Significance) P- value (0.429) is less than 0.05, therefore rejecting the Research hypothesis and accepting the Null hypothesis.

\subsection{2: Analysis of Model - 2}

In model-2, the Experience of the project manager was used as a moderator variable between the independent and dependent variables. Analysis results in model summary reveals that experience of the project manager has no moderating effect on the relationship between independent and dependent variable.

\section{Conclusion and Recommendations}

While using quantitative analysis, no significant correlations have been found stemming from the sample data, so no clear indications have been established of the impact of "switch leadership" on project success in U.A.E. $(r=0.114)$

The data supports the current view that the reactive, one-dimensional project manager will find his or her leadership style may work well under some situations, but is totally unsuited for others.

Findings show that the project manager in U.A.E do not exercises the frequent switch in leadership style during project management, however the frequency of switch in leadership style is very less which is between directing \& coaching leadership style. $(\mathrm{R}-\mathrm{Squared}=0.013)$

There are higher scores on project success factors even when the project manager is seen to have less frequency in switch leadership style, which shows that there are other characteristics of project manager, are involved in project success, such as to have on leadership style throughout the project life cycle, or other organizational environmental factors. 
Findings also show that the experience of project manager does not have significant effect on the relation between switch leadership and project success, as the "p" value slightly increased from 0.429 to 0.597 while tested the effect of project manager's experience as a moderating variable.

\subsection{Conclusion}

According to situational leadership models in general, leaders should adopt different leadership approaches depending on the situations that they encounter. Leadership competencies which work in one given situation may not be effective under different circumstances (Graef, 1983). The increasingly complex project management environment demands for an effective approach to leadership, one that is adaptive to the different followers' situations. The appropriateness of a leadership style changes with change in the leadership environment.

It is increasingly becoming mandatory that project leaders be adaptive (flexible) enough to engage leadership styles that will enhance the success of the project. It is also imperative to note that the leader-follower relationship determines the outcome of any particular task. Lee-Kelley (2002) points out that situational leadership is based on both versatility and effectiveness. Four leadership approaches i.e. directing, coaching, facilitating $\&$ delegating apply under the situational leadership model and are dependent on followers' job-related maturity.

The project Leaders should consider altering styles to achieve the best results with followers and situations, even as they change with time, though other characteristics of project manager and organizational environmental factors contribute to project success.

\subsection{Recommendations}

Findings of the study may get even clearer while opting for larger sample size, since this study was conducted on 50 projects. The impact of switch leadership on project success can be studies on one particular industry's project manager, which may lead to different results of the study. This study can be further extended to include the GCC countries, which may provide different results of study.

\section{References:}

1. Blanchard, K.(May 2008) Leadership Excellence: 25, 5; 19.

2. Clayton, G.(2010) Handbook of research methods, Global media, p. 95.

3. Cindy, M. (2011) Styles of leadership--how to avoid "leisure suits," "high waters," and other career ending mistakes.

4. Guru, P.(2005) switch leadership in projects. 
5. Hersey, P.(2009) Situational leaders: Leadership Excellence. 26, 2, 12.

6. Hans J.(2010) influences of environment and leadership on team performance in complex project environment.

7. Jeffrey, k.,\&dennis, p.(1988), project success: definitions and measurement techniques.

8. Jeffrey, k., \&dennis p. (1991), Project leadership: understanding \& consciously choosing your style.

9. Kerzner, H. (2003). Project management, A systems approach to planning, scheduling and controlling. New York: John Wiley and Sons.

10. Laura, I.(2013), Age as moderator in the relationship between HR development practices and employees' positive attitudes", Personnel Review, Vol. 42 Iss: 6, pp.724 - 744.

11. Benita, Z.__Leadership Communication in Project Management, http:/www.sciencedirect.com/science/article/pii/S187704281402112 0 .

12. Mark, T.(1997), Mastering People Management, Build a Successful Team: Motivate,Empower and Lead People, p 29 \& 3.

13. Nicholas, C. (2012) Leadership in projects: what we know from the literature and new insights, Team Performance Management: An International Journal, Vol. 18 Iss: 3/4, pp.128 - 148

14. Odusami, K. T., Iyagba, R. R. O., \&Omirin, M. M. (2003). The relationship between project leadership, team composition and construction project performance in Nigeria. International Journal of Project Management, 21, 519-527.

15. Phil, N., Megan, H., David, P., (2012) Leadership performance is significant to project success or failure: a critical analysis", International Journal of Productivity and Performance Management, Vol. 61 Iss: 2, pp.204-216.

16. Gina, A.,Project Managers Need Leadership Skills, http://www.projectsmart.co.uk/project-managers-need-leadership-skills.php

17. Rodney,T.,\& Ralf, M.,(2005) The project manager's leadership style as a success factor on projects: a literature review.

18. Smith, W. \& Warnock, J.(1989) Situational theory of leadership, American Journal ofHospital Pharmacy, 46, 11, 2335-2341. http://ajhp.org/content/46/11/2335.abstract.

19. Todd, C. (2013)We Need Project Leadership, Not Managementhttp://www.amanet.org/training/articles/We-Need-ProjectLeadership-Not-Management.aspx

20. Zielasek, G. (1995) Project management for the practitioner successfully activating all levels of the company. Heidelberg, 
Germany: Springer. 